\title{
A MUTAÇÃo VisUAL DO MUNDO SOCIAL
}

\author{
Fabio La Rocca
}

\begin{abstract}
Resumo
Como podemos ver o mundo na sociedade contemporânea? Qual é o papel da visão e das imagens? Nós necessitamos de refletir sobre a nossa época através da hipótese de que nós vivemos numa nova espécie de civilização de imagens onde a vida social é sempre mais condicionada por uma presença e uso massivo de imagens que modificam a conceção fenomenológica da realidade.
\end{abstract}

\section{Palavras-chave}

Imagens; imaginário; fenomenologia; formas visuais; perceções; sociologia visual

\begin{abstract}
How can we see the world in our contemporary society? What is the role of vision and of images? We must reflect on our epoch through the hypothesis that we live in a new kind of a civilisation of images, where social life is more and more conditioned by the presence and the massive use of images that modify the phenomenological conception of the reality..
\end{abstract}

KEYWORDS

Images, imaginary; perceptions; phenomenology; visual forms; visual sociology

Notre appartenance au monde des images et plus fort plus constitutive de notre être, que notre appartenance au monde des idées Gaston Bachelard

An eye for an ear Marshall McLuhan

O processo de compreensão baseia-se na evolução do pensamento ao longo de diferentes épocas que juntam a cultura, a sociedade e o conhecimento. Sabemos que cada época apresenta um tipo particular de pensamento, uma maneira de ver o mundo. Este desenvolvimento constitui a base da revolução científica e da mudança de paradigma. Assim, em cada época, há algo que caracteriza o mundo social, uma espécie de "caráter essencial" enquanto marca da sociedade que caracteriza a reflexão e assim uma outra maneira de ver o mundo, com uma visão diferente. Esta "nova" visão do mundo, enquanto desenvolvimento paradigmático, influencia o processo fenomenológico e gnosiológico de compreensão e significa que está em consonância com a realidade 
do mundo social. Nesse sentido, podemos inspirar-nos na reflexão de Michel Foucault sobre a "ontologia da atualidade"', que é uma resposta à questão de Kant "Was ist Aufklärung?" (1874). Foucault, refletindo sobre a pergunta, "O que é a nossa atualidade?" vê uma nova dimensão de compreensão filosófica no tópico "o que é o nosso presente, o que é isso hoje?". Isso representa ao mesmo tempo uma ontologia da atualidade e uma ontologia de nós mesmos. Neste artigo, limitar-nos-emos a tentar usar as interrogações levantadas por essa questão sem entrar nos detalhes da reflexão de Foucault.

Na verdade, acreditamos que é interessante fazer a pergunta: o que significa "hoje", tendo em consideração a influência das imagens, e também como a nossa realidade é influenciada pela nova forma de ver e de pensar através das imagens. Sabemos que a trajetória da imagem não foi simples, antes de se tornar mais popular e, num sentido lato, antes de ser aceite. Podemos pensar, por exemplo, na relutância das instituições científicas relativamente à sua atitude face aos olhos e aos instrumentos que os prolongam. De facto, no habitus científico, as imagens foram consideradas como uma modalidade excêntrica, desqualificadas como dados e instrumentos. Desde as suas origens, a civilização ocidental desvalorizou a imagem. Uma longa tradição filosófica, pedagógica e científica destruiu as imagens e instalou uma suspeita acerca delas; assim, a imagem, em nome da Razão, foi depreciada, vista como incerta e ambígua. Nesse sentido, um "pensamento sem imagens" domina a cultura. Mais tarde, no século XX, a psicologia junguiana, o neo-kantismo com Heidegger e Cassirer, a fenomenologia de Husserl, a hermenêutica e os estudos da ciência cognitiva revalorizaram as representações visuais e as práticas imagéticas. Isso significa também que uma ruptura epistemológica, que discute a posição do positivismo e do objetivismo das ciências humanas, tomou posição, por exemplo, na figura do teórico do imaginário Gilbert Durand - mas também devemos mencionar Gaston Bachelard - a favor de um novo espírito epistemológico que reavalia a imagem e o imaginário.

Trata-se de uma verdadeira mudança do estatuto das imagens, que começam a ser consideradas de maneira científica, com uma evolução do seu papel, no qual o olho representa uma exploração ativa do universo que está cá para ser visto. Assistimos, assim, a uma mudança importante no que diz respeito à essência das imagens: precisamente, podemos referir-nos à "viragem icónica" de Gottfried Boehm ou a uma "viragem pictórica", como descrita por William Thomas Mitchell (1994), caracterizadas por um nova centralidade das imagens, uma visibilidade e uma visão em diferentes áreas das ciências sociais e humanas. Naturalmente, isso significa dar uma atenção especial a uma dimensão do conhecimento encarnado no poder das imagens, com a capacidade que estas têm para abrir a mente aos múltiplos aspectos do nosso mundo e para descobrir diferentes fragmentos da realidade.

O cinema e a fotografia operam uma profunda transformação do conhecimento e são eficientes para descrever as alterações de visão ligadas à época, porque são meios que podem delinear a relação entre a imagem e o mundo e, em particular, entre a

'A conferência "Qu'est-ce que les Lumières?" foi proferida no Collège de France, em Janeiro de 1983, e publicada em Maio de 1984, no n²07, do Magazine littéraire e podemos encontrá-la posteriormente em Dit et écrits (1994), Paris: Gallimard. 
experiência visível e as noções de compreensão. Devemos recordar que, na sua análise teórica, Jean Epstein fala sobre a cultura visual para colocar em perspetiva o facto de que o cinema contribui para mudar a nossa visão do mundo, num sentido que está relacionado com as mudanças no clima mental de uma época. Desta forma, testemunhamos uma nova viragem do conhecimento, baseado no primado da imagem, que participa no processo de compreensão do mundo. Podemos tomar como exemplo a importante contribuição de Béla Balázs (2010) - enquanto teórico estético do cinema - para a iniciação à cultura visual em Der sichtbare Mensch (1924) e depois em Der Geist des Films (1930), onde explora de que maneira o espírito visual se tornou uma nova dimensão da realidade através da invenção do cinematógrafo. Essa tecnologia é considerada como uma difusão técnica da produção espiritual e como uma tecnologia avançada de ver e de mostrar; para Balázs, o cinematógrafo dá um novo rumo à cultura para o visual. Isto produz também uma nova maneira de ver, ou melhor, uma Weltanschauung, uma expressão que Kant define como sendo a intuição do mundo através dos sentidos e que na linguagem filosófica representa a experiência de vida e uma imagem do mundo. Para nós, há uma Weltanschauung visual, na qual as imagens são um sistema de compreensão e, ao mesmo tempo, uma representação simbólica do mundo, onde temos uma espécie de olhar que caracteriza o olho de uma época, seguindo a teoria de László Moholy-Nagy, que vê uma nova cultura do olhar através do advento da fotografia, enquanto "nova visão", produzindo simultaneamente uma nova experiência sensorial e uma maneira de como ver o mundo de forma nova.

Por isso, compreendemos que a afirmação da primazia das imagens no processo de conhecimento em diferentes épocas suscita muitas reflexões; como testemunha dessa importância, há a afirmação dos Estudos de Cultura Visual nos EUA e no Reino Unido e da Bildwissenschaft - que significa a ciência da imagem - na Alemanha. A posição epistémica da imagem remete para um intenso significado cultural: a importância da visão e da produção de sentido em várias formas de imagens (arte, fotografia, cinema) onde, ao mesmo tempo, é importante refletir sobre as condições da técnica e dos média, permitindo a visualização do mundo, mas também o uso social que os indivíduos fazem das inúmeras imagens que circulam na esfera social.

Essas formas de conhecimento contaminaram a reflexão sobre o mundo social e, neste contexto, podemos afirmar que as imagens se tornam cada vez mais uma especificidade do nosso tempo, o fundamento de uma sensibilidade que caracteriza a expressiva variedade da nossa cultura e da nossa sociedade. Se afirmarmos com Gillian Rose e Nicholas Mirzoeff (2015) que vivemos numa dimensão ocular-central do mundo, isto acontece "não simplesmente porque as imagens visuais são cada vez mais comuns (...), mas porque interagimos com experiências visuais construídas" (Rose, 2012, p. 9). Este ocular-centrismo é frequentemente usado para ilustrar um paradigma visual com uma centralidade do olhar que aponta para uma espécie de imersão numa dimensão de transição, na qual pode emergir um pensamento do olhar e uma ênfase do sensível. $\mathrm{Na}$ tradição, desde Aristóteles, a visão é o sentido predominante, uma fonte de cognição, mas isso não significa que os outros sentidos não sejam importantes no processo de 
perceção e que não participem na definição de formas de atribuição de significados históricos e culturais às relações sociais. Assim, como o afirmou John Berger: "ver precede as palavras" (1972) e hoje a difusão da visualidade aumenta o efeito do ocular-centrismo. Consideramo-lo como uma chave de leitura da pós-modernidade que exibe uma vasta panóplia de imagens através dos novos efeitos dos ecrãs e da tecnologia.

A cultura visual real - ou seja, a relação entre a produção e o consumo de imagens na experiência social - está relacionada com o imaginário, no qual cada pessoa encontra um significado, uma informação, mas também uma fruição e uma religação por meio do uso dos diferentes aparelhos ou interfaces digitais, cujo papel, como Walter Benjamin o ilustrou nos seus trabalhos, está crescendo quase diariamente. Estamos imersos numa "constelação" de imagens que estruturam a nossa experiência de vida quotidiana, como uma espécie de galáxia do imaginário, no qual - inspirado pela análise de Marshall McLuhan - surge um mosaico formado por várias imagens que devemos compreender como uma tática e uma prática numa genealogia da vida quotidiana.

É fundamental pensar que a encenação real do imaginário na nossa cultura deve ser considerada como algo que muda a relação com a realidade social e transforma as identidades. Nesse cenário, o espectador torna-se um espect(a)ator - ou um prossumidor - produzindo uma relação de interatividade com a multiplicidade de imagens que medeiam a nossa vida. Numa climatologia sociocultural, por exemplo, o Instagram pode ser pensado como uma vasta constelação de cenários quotidianos, nos quais cada fragmento é a apresentação de um instante vivido. Assim, a imagem pode ser uma possibilidade de tornar presente o que existe; este é o tempo das imagens e da primazia do imaginário, onde a experiência prática da vida quotidiana está também construída através de uma disposição visual, por meio de uma modalidade visual da nossa relação com e através do mundo. A imagem é o espaço onde consumimos a experiência do mundo, mas, ao mesmo tempo, observando esse cenário de um ponto de vista sociológico, é também uma produção de conhecimento inserida numa relação com o olhar, de forma a proporcionar uma contemplação da dimensão da vida quotidiana. Se o imaginário, de acordo com a perspetiva de Durand, é um denominador onde os procedimentos do pensamento humano são originados, podemos olhar para a realidade social como um mundus de imagens e de imaginários que circundam a esfera do conhecimento.

Do ponto de vista climatológico do nosso tempo, relacionado com o presente, estamos imersos nele e nas suas facetas sociais e culturais, existindo uma proeminência das imagens que sugerem uma mudança de episteme, na qual as próprias imagens, num sentido fenomenológico, colocam a nossa consciência em relação com as coisas e os sentidos, associando, nesta perspetiva, as pessoas com o mundo e o ser, numa espécie de visão da essência. Os diversos aparelhos, como a fotografia, o vídeo, os ecrãs, são formas que desenvolvem uma linguagem atenta de compreensão da realidade, onde a apresentação visual mostra fenómenos sociais. Todas as imagens são integradas numa experiência social e cultural de vida. Isso significa que quando analisamos o mundo social visual, trata-se de um processo de produção de conhecimento. Sabemos que a imagem é um traço do ser humano, que mostra uma presença e que constrói uma memória 
coletiva da vida quotidiana; por isso, a imagem é uma memória permanente do olhar, é eikôn, que significa "tornar presente". Isto parece ser uma das características essenciais da capacidade das imagens na nossa contemporaneidade.

A galáxia de imagens representa um modelo expressivo, uma demonstração (monstration) ativando um impacto sensorial que influencia o pensamento. Sabemos ainda, como Rudolf Arnheim teorizou, que a perceção visual significa pensamento visual. Assim, a perceção visual transforma o que é visto em noções e reflexões do pensamento. Nesse contexto, a nossa imersão na atmosfera visual leva-nos a constatar uma forte analogia entre o conteúdo simbólico das imagens e a realidade. Ao mesmo tempo, não devemos esquecer que as imagens nos oferecem fragmentos e detalhes da realidade que são selecionados de forma subjetiva, contribuindo para a construção do pensamento e do conhecimento. A visualização da realidade permite-nos dar uma definição subjetiva específica, que é o processo de produção de uma visão particular do mundo.

O uso de imagens na construção da realidade social é uma perspetiva pertinente para ver a realidade, envolve as coisas e estabelece uma ordem simbólica. Assim, se nos interrogamos sobre como fabricamos uma construção social da realidade - pensando na famosa obra de Peter L. Berger \& Thomas Luckmann - podemos considerar a imagem como uma componente desse processo, participando na criação e na recriação da intersubjetividade, significando que múltiplas realidades coexistem em qualquer contexto. Essa coexistência também pode ser percebida com a consideração de que a imagem, do ponto de vista de Michel Maffesoli (1993), é "mesocosmo": um elemento intersticial entre o macrocosmo e o microcosmo. Com a sua função de religação, convida-nos a compreender o mundo social. Por outro lado, a imagem corresponde a um espelho da sociedade, e sabemos que o espelho é uma figuração simbólica da imagem, na qual se condensa a sua problemática ontológica. O espelho - analisado por Platão, Leibniz, Lacan - forma uma figuração simbólica da imagem, um centro de alteridade e de identidade que devemos levar em consideração ao capturar os sinais expressivos do nosso presente. Do ponto de vista do processo simbólico, esta análise pode estar relacionada com a ideia, na construção da realidade social, de se conceber a si próprio através de outros: o "efeito de espelho social" (looking glass self), disse Charles H. Cooley, em 1902, para ilustrar como os outros são o espelho de nós próprios. E este espelho do ambiente contemporâneo pode ser ilustrado, por exemplo, ao partilhar instantes da nossa vida através de diferentes fotografias. $\mathrm{E}$, ao mesmo tempo, esse "espelho" também pode ser ilustrado pela fenomenologia da selfie, uma atitude típica dos nossos tempos que significa, igualmente, uma presença que transmite uma relação. A selfie, enquanto auto-retrato do século XXI, é um desejo de estar-aí, uma demonstração de participação no mundo. Os média sociais satisfazem a nossa identidade e cultura, são uma apresentação de nós mesmos com a abertura aos outros. Neste sentido, a "selficação" da realidade é uma chave para a leitura da prática social orientada para os outros, na qual a religação é o processo de um estar no mundo, no qual o indivíduo, no processo da relação social, se ajusta ao seu ambiente social. Do ponto de vista de uma abordagem sociológica, sabemos que estamos ligados aos outros e à sociedade para satisfazer a necessidade vital de 
um reconhecimento social, a nossa identidade e existência. Este é também um sintoma, construir através das imagens uma estética da existência, que na nossa época se tornam em afinidades, tipificadas por Vincenzo Susca (2017) como "afinidades conectadas".

Bem, as várias imagens que circulam na esfera social são uma expressão da figuração simbólica do espelho que reúne a alteridade e a identidade, gerando um caleidoscópio da nossa existência, com laços e comunhão. Este processo de mimesis é também a expressão de uma dependência do outro e do aparelho visual através do qual os indivíduos experienciam a sua vida quotidiana. A Erlebnis visual é um ato no nosso mundo social, onde os símbolos, as imagens e o imaginário são condição de possibilidade da experiência e, ao mesmo tempo, tornam possível uma intensa compreensão do sentido de realidade que as pessoas expressam.

Quanto à perceção, é óbvio que quando falamos sobre a perceção da experiência devemos também prestar atenção à estrutura técnica, aos aparelhos que nos permitem ampliar a realidade. Na verdade, existem algumas alterações sensoriais que influenciam o nosso modo de perceção e de visão. Lá onde há uma interação com as interfaces que se interpõem entre nós e o mundo, há a produção de uma penetração tecno-simbólica que modifica as perceções sensoriais. Estamos diante de uma visualização percetiva do ser e das suas formas de habitar o mundo que gera uma cine-presença, uma foto-presença e uma imago-presença. A visualização é um instantâneo da experiência, onde os ecrãs se tornam como próteses da explosão da visualidade que influencia a maneira como agimos. Nesse sentido, podemos questionar a natureza de nossa relação com o ecrã? Os ecrãs são superfícies de projeção da nossa existência e presença, a manifestação e uma aparência que tornam possíveis, ou melhor dito, que tornam visíveis o mundo e o estar-aí. Assim, é apropriado falar de ecrãnologia, onde o ecrã representa uma superfície vivida e, consequentemente, é apropriado olhar para as relações intermediais como formas culturais ${ }^{2}$. Hoje em dia, não podemos negar o importante impacto dos ecrãs, que são extensões permanentes dos nossos corpos; mas o ecrã é naturalmente um totem da nossa relação com o mundo e na nossa sociedade contemporânea pode ser visto como uma forma narrativa e um processo de identificação que transforma a prática de visualização da vida quotidiana. Se o olhar do mundo social é mediado por imagens, o ecrã tem uma natureza ontológica que significa que não é um simples dispositivo tecnológico, mas um dispositivo óptico que caracteriza a nossa maneira de estarmos no mundo e a nossa relação com o real. A realidade é o ecrã porque aparece através do ecrã e, ao mesmo tempo, o ecrã é um meio que estabelece o contacto com a realidade, na qual, segundo a perspetiva de Merleau-Ponty (Carbone, 2011), vemos através e com o ecrã.

\section{Tradução de Jean-Martin Rabot, CECS}

\footnotetext{
${ }^{2}$ Vejam, por exemplo, as reflexões de Lev Manovich e Erkki Huhtamo. The screen media reader. Culture, theory, practice, editado por S. Monteiro (2017), New York: Bloomsbury.
} 


\section{REFERÊNCIAS BIBLIOGRÁFICAS}

Balázs, B. (2010). L'homme visible et l'esprit du cinéma. Belfort: Circé.

Carbone, M. (2011). La chair des images: Merleau-Ponty entre peinture et cinéma. Paris: Vrin.

Berger, J. (1972). Ways of seeing. Londres: Penguin Books Ltd.

Foucault, M. (1983). Qu'est-ce que les Lumières? Comunicação apresentada no Collège de France,Paris.

Foucault, M. (1994). Dit et écrits. Paris: Gallimard.

Maffesoli, M. (1993). La contemplation du monde. Paris: Grasset.

Manovich, L. \& Huhtamo, E. (Eds.) (2017). The screen media reader. Culture, theory, pratice. Nova lorque: Bloomsbury.

Mitchell, W. J. T. (1994). Picture theory. Essays on verbal and visual representation. Chicago: University of Chicago, Press.

Mirzoeff, N. (2015). How to see the world. Nova lorque: Pelican.

Monteiro, S. (2017). The screen media reader. Culture, theory, practice. Nova lorque: Bloomsbury.

Rose, G. (2012). Visual methodologies: An introduction to interpreting visual materials. Londres: Sage.

Susca, V. (2017). Les affinités connectives. Sociologie de la culture numérique. Paris: Cerf.

\section{NOTA BIOGRÁFICA}

Doutor em Sociologia, Maître de conférences na Universidade Paul-Valéry, Investigador no Centre d'Études sur l'Actuel et le Quotidien (Paris Descartes Sorbonne)

E-mail: fabio.la-rocca@univ-montp3.fr

Departamento de sociologia, IRSA-CRI, Universidade Paul-Valéry Montpellier 3

Route de Mende , 34199 Montpellier Cedex 5, França

$\because$ Submetido: 03/03/2017

* Aceite: 25/04/2017 